\title{
Effectiveness of outrigger and belt truss systems on the seismic behavior of high-rise buildings
}

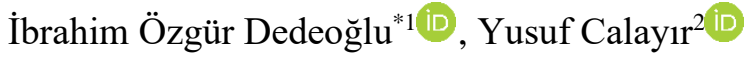 \\ ${ }^{1}$ Batman University, Department of Civil Engineering, Batman, Turkey \\ ${ }^{2}$ Firat University, Department of Civil Engineering, Elazığ, Turkey
}

\begin{abstract}
The outrigger systems, which is widely used with shear wall-framed systems at the tall buildings, increase the lateral stiffness of the structural bearing system and reduce the lateral drift of the structure under lateral loads. However, the traditional outrigger systems, besides these positive contributions, also create some limitations and problems affecting the modeling of the structure. Some of these; more interior space occupying as an architect, problems arising in the connection of outrigger and center core (especially when a concrete shear-wall core is used). On the other hand, the belt trusses known as "Virtual Outriggers" which have recently been used to build high-rise structures, have removed these problems. Unlike the traditional outrigger systems, belt trusses are formed between the outer columns. In this way belt trusses eliminate the problems arising from the direct connection of the outriggers to the center core and other problems associated with using outriggers. Extensive studies have been carried out on the examination of outrigger and belt truss systems used in high-rise buildings under static and dynamic loads. In this study, the linear earthquake responses of three structural models, which are shear wall-framed system, shear wall-framed system with traditional outriggers and shear wall-framed system with belt trusses, were performed by using modal time history analysis method. Lateral displacements and drifts of the structure, internal forces of the structural elements were obtained. These results of three structural models were compared with each other and the effectiveness of outrigger and belt truss systems were assessed. For earthquake input, three real earthquake records were selected. These records were scaled in accordance with the DD2 level earthquake design spectrum defined in Turkish Building Earthquake Standards (2018) and used in the analyses.
\end{abstract}

\section{Keywords}

Tall building; Shear wall-framed system; Outrigger; Belt-truss; Earthquake response.

Received: 20 September 2019; Accepted: 16 September 2020

ISSN: 2630-5763 (online) C 2020 Golden Light Publishing All rights reserved.

\section{Introduction}

From the beginning of the 20th century, innovations in materials and the rapid development of computer technology enabled the construction of multi-story buildings. The production of high-strength concrete, the use of steel and composite elements, and the use of computers in structure analyzing under loads, especially of structures with complex loads, allowed the number of floors to be reached from typical 5-10 stories to 100 .

The vertical loads, which are the primary factors in the forming a structural model and design of the load bearing system, leave its place to the horizontal loads with the increase of the building height.

* Corresponding author

Email: iozgur.dedeoglu@batman.edu.tr 
Lateral stiffness is a directly significant influence to resist on the horizontal loads, which are wind and earthquake loads. Therefore, the selection and modeling of a horizontal load bearing system which resist to the effects of the predicted horizontal loads has become extremely important. The framed systems that successfully meet the horizontal loads up to the 20-storey structure, with the addition of the shear wall, become the horizontal load carrier system suitable for the number of floors 40-50. However, shear wall-framed systems alone cannot provide sufficient lateral rigidity to resist increased horizontal loads due to the increase in building height depending on the increase in the number of building floors. In this case, the outrigger and belt truss systems used with the shear wall-framed system contribute significantly to the lateral stiffness and bending moment rigidity of the structure under horizontal loads.

\subsection{Literature review}

Simplified analytical and graphical method solutions for high-rise structures with the outrigger systems began nearly 40 years ago. Taranath $[1,2]$ considered the design of structure systems with one outrigger and suggested that the optimum location of one outrigger should be close to the mid-height of the structure. McNabb and Muvdi [3, 4] showed that the structural properties of the shear wall and the columns are significant design parameters in reducing lateral deflections and suggested a solution for a structure system with two outriggers. Stafford Smith and Salim [5] were studied the behavior of outrigger-braced tall building structures taking into account the flexibility of the outriggers. Nair [6] investigated the efficiency of the belt trusses, which are also called as "virtual outriggers" system and placed between the outside columns. In that study, belt trusses are not connected with the shear wall directly and they used instead of the traditional outrigger systems. Hoenderkamp and Snijder [7] investigated analytically the behavior of high-rise structures under horizontal loads using the belt trusses, which are not directly connected by shear walls, placed between columns and called as facade riggers. Hoenderkamp and Bakker [8] was investigated analytically the behavior of the structure with outrigger system subjected to horizontal loads. In the analytical solution of the outrigger system, shear deformations were taken into account besides the bending deformations. Hoenderkamp [9] conducted an analytical study in which two-level outrigger systems were considered and kept constant the position of the outrigger system located on the top of the structure. He investigated optimum position of the second outrigger system by considering the peak displacement and shear wall base moment.

Rahgozar et al. [10] performed an analytical research on high-rise structures and proposed a simple hand calculations method for approximate analysis of framed tube, shear core and belt truss systems in high rise buildings subjected to lateral loads such as wind and earthquake. This method has yielded quite satisfactory results. Kamath et al. [11] investigated the effect of bending stiffness of outrigger system to the structure. They studied the effects of the positional changing and bending stiffness of the outrigger system on the lateral displacements, shear forces and bending moments of the shear wall. Nanduri et al. [12] conducted a numerical study on the high-rise structure with outrigger systems. They were examined the behaviors of shear wall-framed systems with traditional outriggers and shear wall-framed systems with traditional outriggers and belt trusses under vertical and lateral loads. Zhou et. al [13] carried out an analytical study on the optimal placement of the outriggers along the building height. They expressed that the inter-story drift is a more important engineering demand parameter for tall buildings and the inter-story drift-based optimal location is practical and efficient. Patil and Sangle [14] investigated the seismic behavior of outrigger braced building to find out the optimum location of outrigger in high rise 2D steel buildings. Dedeoğlu [15] made an analytical research on high-rise structures with outrigger systems under static lateral loads. Calayır and Dedeoğlu [16] investigated the earthquake responses of shear wallframed systems with and without outriggers by using linear analysis method in time-domain. Two 
structural systems had same storey plan and same structural members that are core, columns and beams. They evaluated effectiveness of the outrigger systems by comparing the earthquake responses of both structural systems with each other. Kamgar and Rahgozar [17] presented a methodology for determining the optimum location of a flexible outrigger system in tall buildings. The methodology is based on maximizing the outriggerbelt truss system's strain energy. Rabee and Juan [18] studied on the approximate analysis of reinforced concrete outriggers which are commonly used in the design and construction of supertall buildings subject to distributed horizontal loads. Mohsenali et al. [19] investigated numerically and parametrically the effect of the combined system of outrigger and steel coupled shear walls on the control of the lateral displacements of a tall building structure. The results indicate that the location of an outrigger is more significant than its rigidity. Lin and Takeuchi [20] investigated the seismic behavior of structures with a single layer bucklingrestrained brace-outrigger. They proposed three types of buckling-restrained brace-outrigger configurations for practical design purposes that fit different architectural requirements. Fathy [21] studied the seismic performance and failure modes of the dual system of moment resisting frames and thin steel plate shear walls (TSPSWs) without and with one or two outrigger trusses. Dedeoğlu et al. [22] made an analytical research on high-rise structures with outrigger systems and examined the effectiveness of the outrigger systems. Akbar and Vahid [23] evaluated seismic behavior of a 40-story building using steel plate shear wall structural system with and without outriggers. The outrigger panels were placed in 20th, 30th, and 40th story levels and the effectiveness of these elements on the overall seismic behavior was studied. Kirruti and Balkis [24] assessed the seismic performance of concentric steel bracing systems in high-rise reinforced concrete structures.

\subsection{Outrigger systems}

In recent years, while horizontal and vertical load bearing models of high structures have been formed, systems with a shear wall system at the center of the structure plan and columns at the outboard of plan are preferred. The interaction between the central shear wall and the frame columns on the outer is provided by beams and floors. However, in certain regions of the building height, rigid horizontal elements usually formed from steel brace bars are placed between the shear wall and the columns so that the cooperation and interaction between these two bearing elements is stronger. The basic function of these structural elements, called the outrigger system, is to strengthen the mutual interaction between the shear wall and the frame columns, and in particular to increase the lateral stiffness and bending rigidity against horizontal loads. The outrigger system can be applied in one or several floors in construction. The representation of this system in the floor plan is given in Fig. 1a. In addition, this system, which is generally applied bilaterally, can also be applied unilaterally depending on the building model. These application forms are shown in Figs. 1b-c [25]. The outrigger systems are placed homogeneously in along the height of structure.

The behavior of the outrigger system in the building system under horizontal loads is quite simple and effective. When the effect of horizontal loads and structures will provide strong collaboration between the center shear wall and the outer column and will thereby limiting an amount of rotation and translation of the shear wall. Thanks to this interaction, the shear wall with outrigger will show less rotational and horizontal drift than the shear wall without outrigger. This situation is shown in Fig. 2 [25]. In addition, the bending moment generated in the structure under the influence of the horizontal forces will be compensated not only by the center shear wall but also by the tension and pressure force pairs in the outer columns, which are formed by means of the outrigger system. The operating principle of this system, in which significantly increases the bending resistance capacity of the load bearing system, is shown in Fig. 3 [6]. 


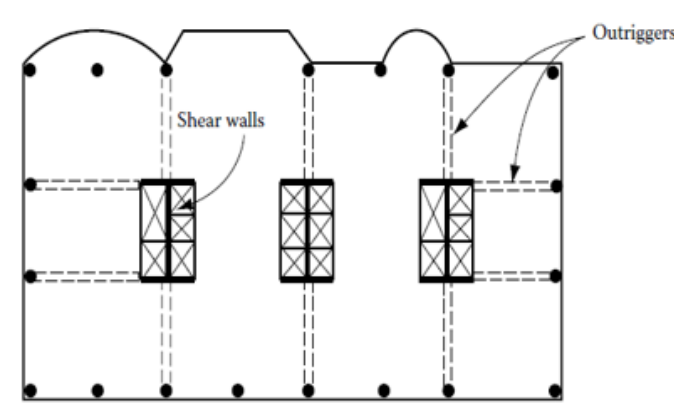

a)

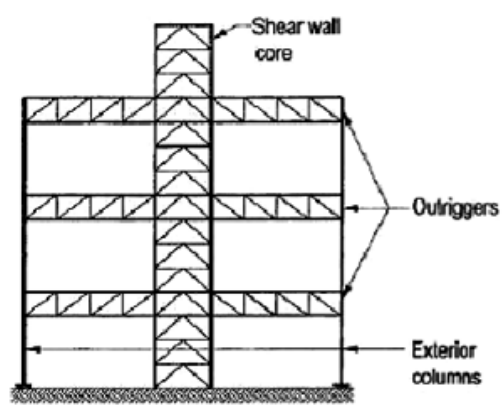

b)

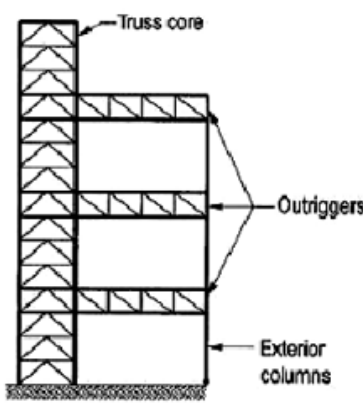

c)

Fig. 1. Outrigger systems (a) plan view (b) bilaterally application (c) unilaterally application [25]

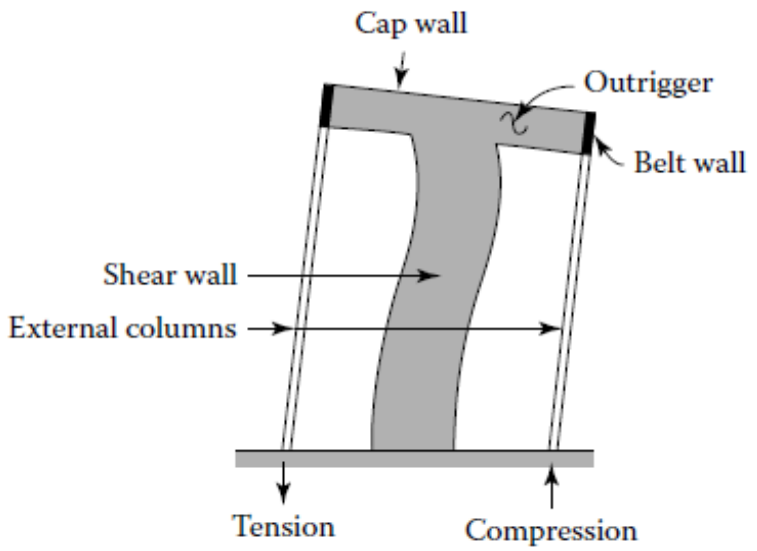

Fig. 2. Reducing rotation and displacement of core wall [25]

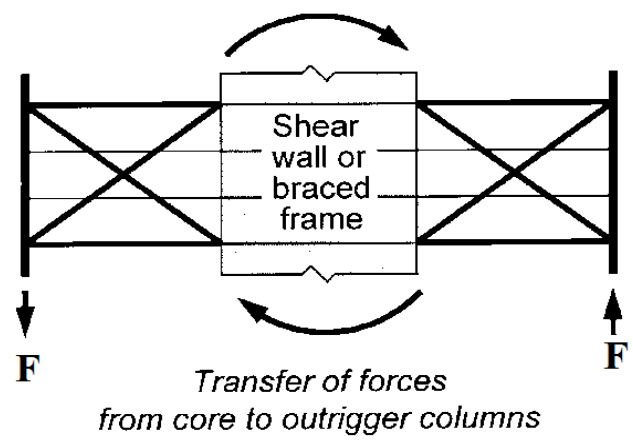

Fig. 3. Force transfer from core to outrigger column [6]

There are several problems associated with the use of outriggers that limit the applicability of the concept in the real world:

1. The space occupied by the outrigger trusses (especially the diagonals) places constraints on the use of the floors at which the outriggers are located. Even in mechanical equipment floors, the presence of outrigger truss members can be a major problem.

2. Architectural and functional constraints may prevent placement of large outrigger columns where they could most conveniently be engaged by outrigger trusses extending out from the core. 
3. The connections of the outrigger trusses to the core can be very complicated, especially when a concrete shear wall core is used.

4. In most instances, the core and the outrigger columns will not shorten equally under gravity load. The outrigger trusses, which need to be very stiff to be effective as outriggers, can be severely stressed as they try to restrain the differential shortening between the core and the outrigger columns. Elaborate and expensive means, such as delaying the completion of certain truss connections until after the building has been topped out, have been employed to alleviate the problems caused by differential shortening [6].

\subsection{Belt truss systems as a virtual outrigger}

In the traditional outrigger concept, outrigger trusses connected directly to the core and to outboard columns convert moment in the core into a vertical couple in the columns. In the "virtual" outrigger concept, the same transfer of overturning moment from the core to elements outboard of the core is achieved, but without a direct connection between the outrigger trusses and the core. The elimination of a direct connection between the trusses and the core avoids many of the problems associated with the use of outriggers.

The basic idea behind the virtual outrigger concept is to use floor diaphragms, which are typically very stiff and strong in their own plane, to transfer moment in the form of a horizontal couple from the core to trusses or walls that are not connected directly to the core. The trusses or walls

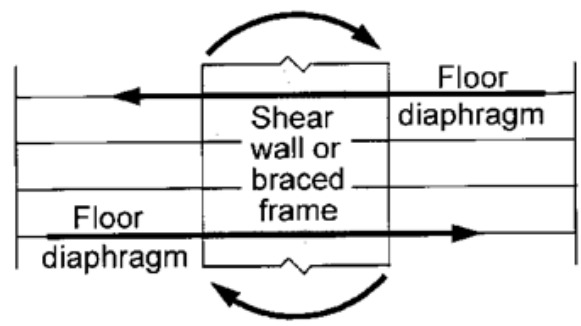

(a) Transfer of forces from core to floor diaphragms then convert the horizontal couples into vertical couples in columns or other structural elements outboard of the core. Belt trusses and basement walls are well suited to use as virtual outriggers.

Fig. 4 is an elevation of a building similar to the structure in Fig. 1 except that it has belt trusses at the exterior, instead of conventional outrigger trusses between the core and the exterior.

The way in which overturning moment in the core is converted into a vertical couple at the exterior columns is shown in Fig. 4 [6]. Rotation of the core is resisted by the floor diaphragms at the top and bottom of the belt trusses; thus, part of the moment in the core is converted into a horizontal couple in the floors (Fig. 4a). The horizontal couple, transferred through the two floors to the truss chords, is converted by the truss into vertical forces at the exterior columns (Fig. 4b).

The forces and moments in all components can be determined by three-dimensional elastic analysis of the lateral load-resisting system, which includes the core, the trusses, the exterior columns, and the floors that connect the core to the trusses. The inplane stiffness of the floors at the top and bottom of each outrigger should be represented accurately in the analysis (such as through the use of planar finite elements). These floors should not be regarded as infinitely stiff diaphragms.

When the core is a steel braced frame, the transfer of horizontal forces between the core and the floors can be achieved through shear studs on the horizontal frame members. When the core is a concrete shear wall, forces may be transferred through the concrete-to-concrete connection, with reinforcing steel extending through the connection.

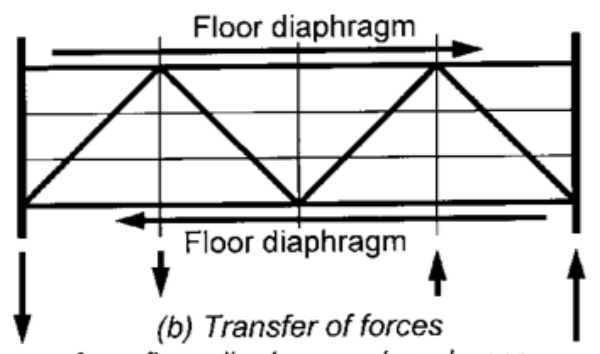

from floor diaphragms to columns through belt truss

Fig. 4. Force transfer using belt truss as virtual outrigger [6] 
The transfer of horizontal forces between the floor diaphragms and the chords of the belt trusses can be achieved through shear studs on the chords.

The floor slabs that transfer horizontal forces from the core to the belt trusses will be subjected to in-plane shear (in addition to the usual vertical dead and live load effects) and should be proportioned and reinforced appropriately. In many applications, it will be necessary to use thicker-than-normal slabs.

The use of belt trusses as virtual outriggers avoids many of the problems associated with the use of conventional outriggers, including all four of the items listed previously under "Problems with Outriggers":

1. There are no truss diagonals extending from the core to the exterior of the building.

2. The need to locate outrigger columns where they can be conveniently engaged by trusses extending from the core is eliminated.

3. The complicated truss-to-core connection is eliminated.

4. Differential shortening or settlement between the core and the outboard columns does not affect the virtual outrigger system since the floor diaphragms, though stiff in their own plane, are very flexible in the vertical, out-ofplane direction [6].

\section{Numerical Application}

\subsection{Models presentation and ground motion selection}

In this study, three 60 -story building models which are shear wall-framed system (Model 1), shear wall-framed system with traditional outriggers (Model 2) and shear wall-framed system with belt trusses (Model 3), respectively, are constructed with the same floor plans. Floor plans of the all models are shown in Fig. 5. The plan has 5 spans in the $\mathrm{x}$ direction and 5 spans in the $\mathrm{y}$ direction and the span distances are $6 \mathrm{~m}$. The elevation views of the study models are given in Fig. 6. Model 2 is formed by adding the outriggers in the four levels to the shear wall-framed system (Fig. 6).

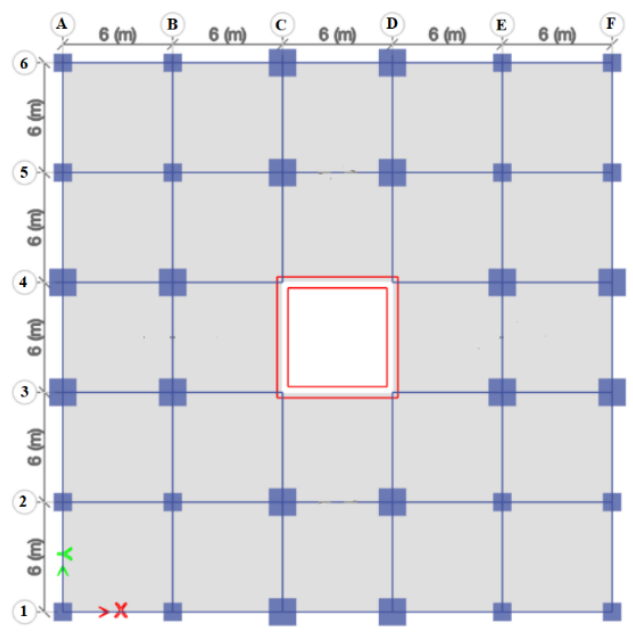

Fig. 5. Plan view for all structural models

In each level, the outriggers are located at the axes 3 and 4 in the $x$-direction and also at the axes $C$ and $\mathrm{D}$ in the $y$-direction (Fig. 5). Model 3 is obtained by adding steel braces to the outer columns of the shear wall-framed system in the four levels (Fig. 6).

The structural element properties (shear wall, column, beam and slab) of the three models are identical. In all structural models, the structural element properties are kept constant throughout the building height. Floor heights and floor thicknesses in the models are taken as $3.0 \mathrm{~m}$ and $0.20 \mathrm{~m}$ respectively. The structural element properties of the models are given in Table 1. The sections of the structural elements of the outriggers are selected in the form of circle.

The three real earthquakes records are taken from the strong ground motion database of Pacific Earthquake Engineering Research Center [26]. These records belong to earthquakes with moment magnitudes in the range 6.5 to 7.5 and their peak acceleration (PGA) values are in the range of $0.3 \mathrm{~g}$ to $0.35 \mathrm{~g}$, where $\mathrm{g}$ is the gravitational acceleration. Names and major seismological parameters of the selected records are presented in Table 2, where $M_{w}$ is the moment magnitude of earthquake, PGV and PGD are the peak values of ground velocity and ground displacement, respectively. 


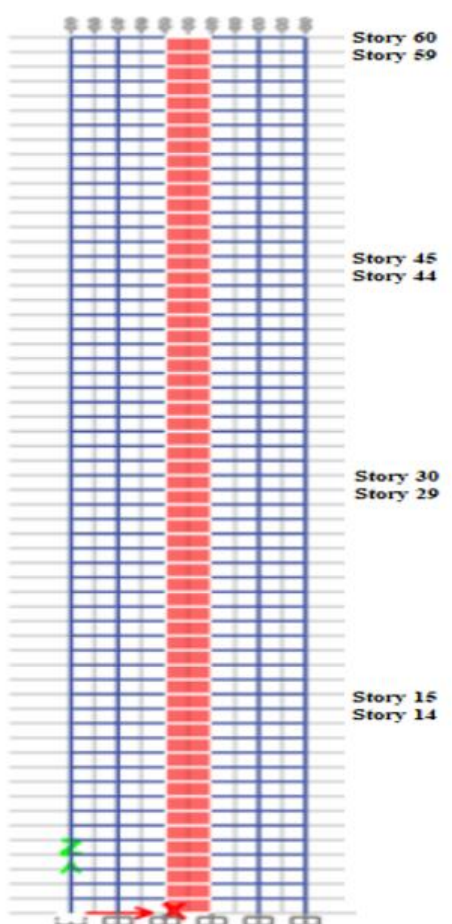

Model 1

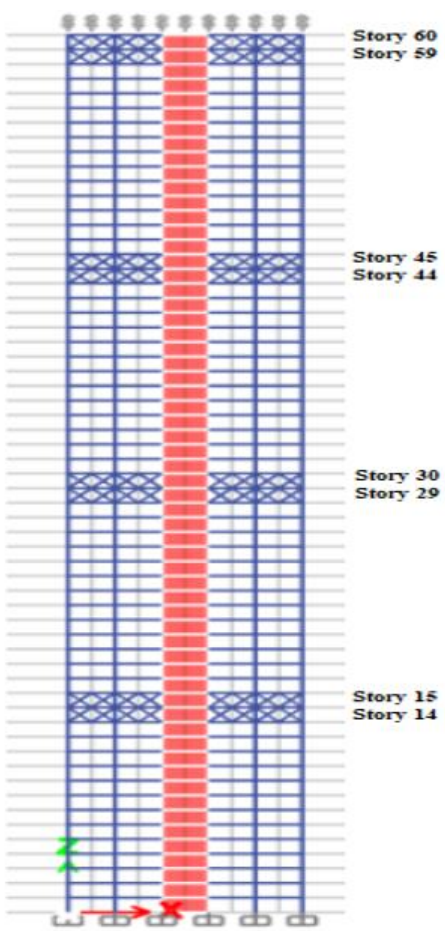

Model 2

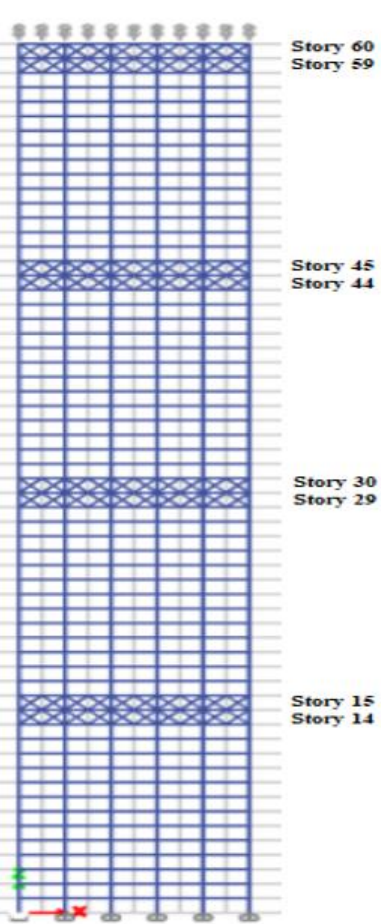

Model 3

Fig. 6 Elevation views of the structural models

Table 1. Structural properties of models

\begin{tabular}{llll}
\hline \multirow{2}{*}{ Structural Element } & \multicolumn{3}{c}{ Section Properties } \\
\cline { 2 - 4 } & $\begin{array}{l}\text { Model 1 } \\
\text { (Shear Wall-Framed }\end{array}$ & $\begin{array}{l}\text { Model 2 } \\
\text { (Shear Wall-Framed } \\
\text { System) }\end{array}$ & $\begin{array}{l}\text { Model 3 } \\
\text { (Shear Wall-Framed }\end{array}$ \\
& $0.6 \times 6 \mathrm{~m}^{2}$ & $0.6 \times 6 \mathrm{~m}^{2}$ & $0.6 \times 6 \mathrm{~m}^{2}$ \\
Shear walls & $1.5 \times 1.5 \mathrm{~m}^{2}$ & $1.5 \times 1.5 \mathrm{~m}^{2}$ & $1.5 \times 1.5 \mathrm{~m}^{2}$ \\
Huge Columns & $1.0 \times 1.0 \mathrm{~m}^{2}$ & $1.0 \times 1.0 \mathrm{~m}^{2}$ & $1.0 \times 1.0 \mathrm{~m}^{2}$ \\
Columns & $0.4 \times 0.6 \mathrm{~m}^{2}$ & $0.4 \times 0.6 \mathrm{~m}^{2}$ & $0.4 \times 0.6 \mathrm{~m}^{2}$ \\
Beams & $0.4 \times 1.0 \mathrm{~m}^{2}$ & $0.4 \times 1.0 \mathrm{~m}^{2}$ & $0.4 \times 1.0 \mathrm{~m}^{2}$ \\
Deep Beams & --- & $\mathrm{D}=0.3 \mathrm{~m}, \mathrm{t}=0.05 \mathrm{~m}$ & --- \\
Outrigger braces & --- & --- & $\mathrm{D}=0.3 \mathrm{~m}, \mathrm{t}=0.05 \mathrm{~m}$ \\
\hline
\end{tabular}

Table 2. Major seismological parameters of the ground motions

\begin{tabular}{|c|c|c|c|c|c|c|c|}
\hline Record Name & $\begin{array}{l}\text { Earthquake \& } \\
\text { Year }\end{array}$ & Station & $\mathrm{M}_{\mathrm{w}}$ & $\begin{array}{l}\text { Arias Intensity } \\
(\mathrm{m} / \mathrm{s})\end{array}$ & $\begin{array}{l}\text { PGA } \\
(\mathrm{g})\end{array}$ & $\begin{array}{l}\mathrm{PGV} \\
(\mathrm{cm} / \mathrm{s})\end{array}$ & $\begin{array}{l}\text { PGD } \\
(\mathrm{cm})\end{array}$ \\
\hline $\begin{array}{l}\text { RSN178_IMPVALL.H_H- } \\
\text { E03140 }\end{array}$ & $\begin{array}{l}\text { Imperial } \\
\text { Valley, } 1979\end{array}$ & El Centro & 6.5 & 1.26 & 0.3152 & 42.67 & 11.12 \\
\hline RSN1107_KOBE_KAK090 & Kobe, 1995 & Kakogawa & 6.9 & 1.68 & 0.3242 & 26.89 & 9.00 \\
\hline RSN1176_KOCAELI_YPT150 & Kocaeli, 1999 & Yarımca & 7.51 & 1.32 & 0.3210 & 71.86 & 47.08 \\
\hline
\end{tabular}


These records were scaled to be in accordance with the DD2 level design spectrum defined in the Turkish Buildings Earthquake Standards (2018) using the Seismo Match 2016 program to obtain the earthquake response of the structural models.

It is assumed that the structural models are located in İzmir province 38.44 latitude and 27.17 longitude and has ground class ZB. The scaled earthquake acceleration records were shown in Fig. 7. Comparison of the code design spectrum-DD2 level with response spectra of the scaled earthquakes records was given in Fig. 8.

The earthquake excitation has been applied to each model in the horizontal $\mathrm{x}$ direction. The linear solutions of the all structural models under each earthquake record were obtained by using the modal solution method based on time history analysis (MTHA), respectively. The time step was chosen $0.01 \mathrm{~s}$ and the damping ratio was assumed to be 0.05 in all modes. ETABS [27] program was used in the solutions.

\subsection{Model results}

Some results obtained from the linear earthquake response analyses of the all structural models are given below. Dead, live and the earthquake loadings were taken into account in the analyses of the all models. As the mass source, all dead load and $30 \%$ of live load were selected.

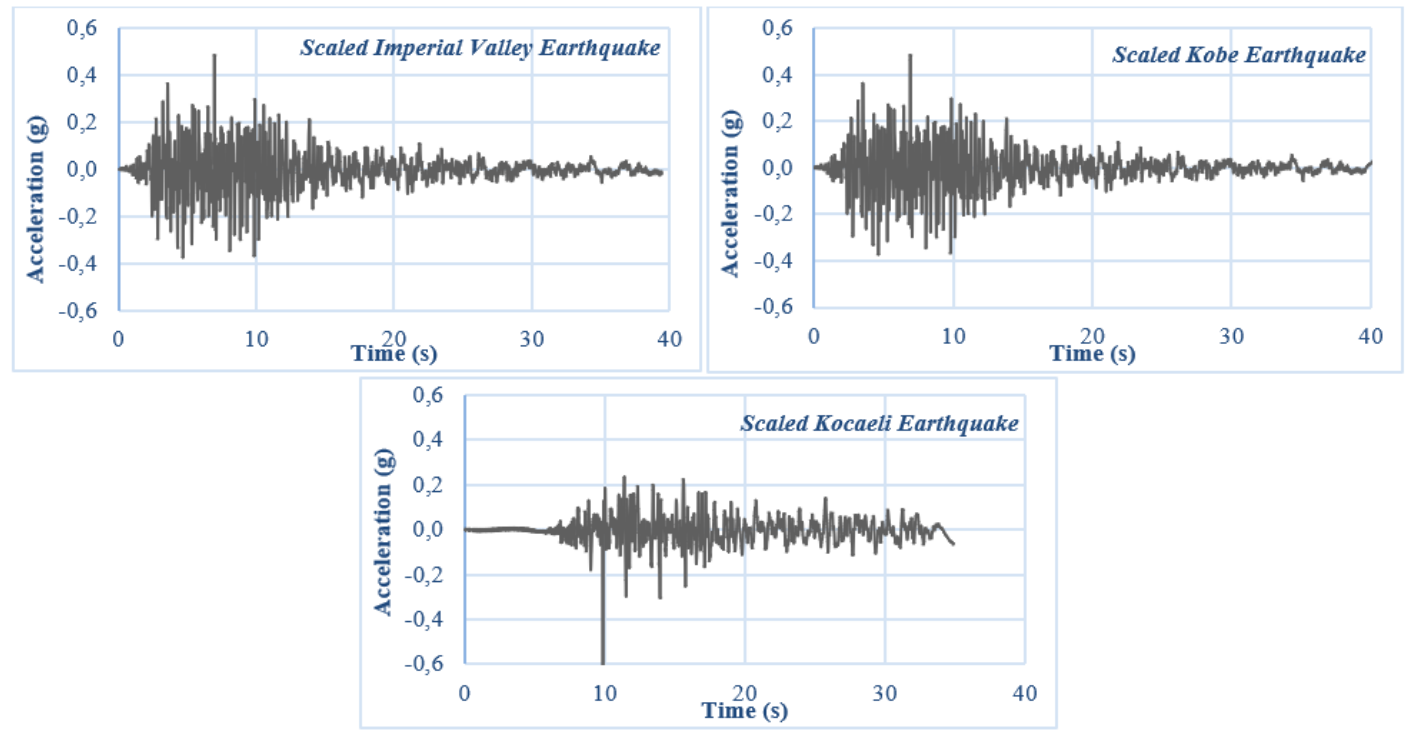

Fig. 7. Acceleration time histories of scaled earthquakes records

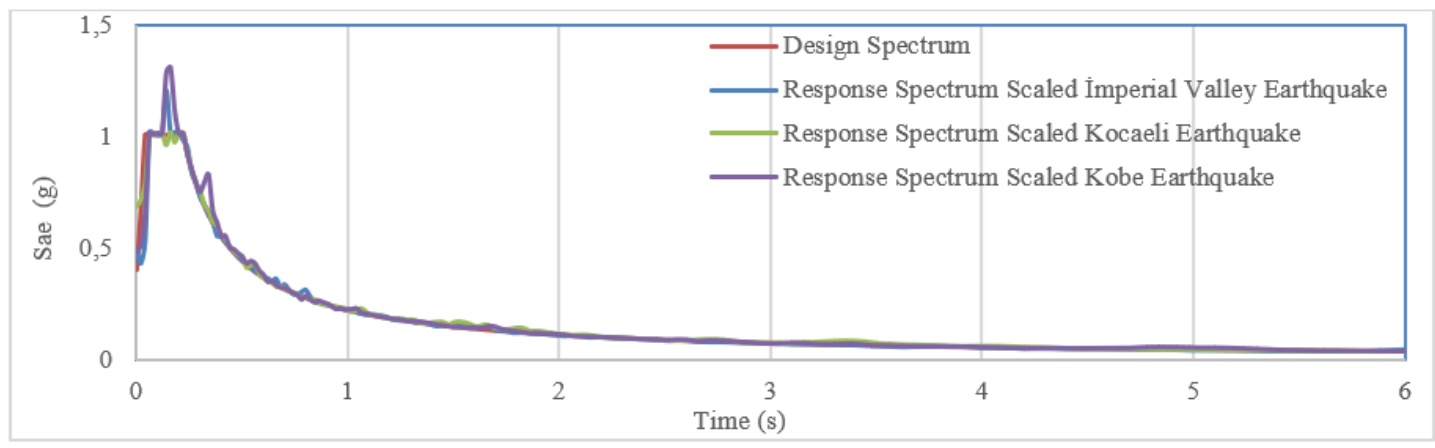

Fig. 8. Comparison of the code design spectrum-DD2 level with response spectra of the scaled earthquakes records 
Number of modes was considered as 24 in the modal solution method based on time history analysis (MTHA). The total effective mass ratios in the $x$ and $y$-horizontal directions and the total torsional effective mass ratio exceeded $95 \%$ for the selected mode number. The modal mass participation ratios of the first six modes with including predominant ones are given in Tables 3-5 for all models. As the structural models are symmetrical in plan, the values of predominant periods related with translation motion in $\mathrm{x}$ and $\mathrm{y}$ directions are equal for each structural model. The periods are obtained as 4.911, 4.407 and 4.453 seconds, respectively, for all models. In this case, it can be said that the outrigger and belt-truss systems increase lateral stiffness of the building system.
However, the outrigger systems increased the lateral stiffness slightly more than belt-truss systems. The predominant torsional periods are obtained as 3.489, 3.462 and 3.162 seconds, respectively, for all models. Hence, it can be said that the outrigger and belt-truss systems increase the torsional rigidity of the structural system. However, the belt-truss systems increased the torsional stiffness slightly more than outrigger systems.

The maximum displacement values obtained from the analyses of structural models are given in Table 6. The maximum lateral displacement and lateral drift curves of the structural models under the scaled Kocaeli earthquake record are given in Figs. 9-10, respectively.

Table 3. Modal periods and mass participation ratios of Model 1

\begin{tabular}{llllllll}
\hline Mode & Period $(\mathrm{s})$ & $\mathrm{UX}$ & $\mathrm{UY}$ & $\mathrm{RZ}$ & $\Sigma \mathrm{UX}$ & $\Sigma \mathrm{UY}$ & $\Sigma \mathrm{RZ}$ \\
\hline 1 & 4.911 & 0.7117 & 0.0024 & 0 & 0.7117 & 0.0024 & 0 \\
2 & 4,911 & 0.0024 & 0.7117 & 0 & 0.7144 & 0.7144 & 0 \\
3 & 3.489 & 0 & 0 & 0.7997 & 0.7144 & 0.7144 & 0.7997 \\
4 & 1.425 & 0.1417 & 0.0003 & 0 & 0.8557 & 0.7147 & 0.7997 \\
5 & 1.425 & 0.0003 & 0.1417 & 0 & 0.8562 & 0.8562 & 0.7997 \\
6 & 1.157 & 0 & 0 & 0.0909 & 0.8562 & 0.8562 & 0.8906 \\
\hline
\end{tabular}

Table 4. Modal periods and mass participation ratios of Model 2

\begin{tabular}{llllllll}
\hline Mode & Period $(\mathrm{s})$ & $\mathrm{UX}$ & $\mathrm{UY}$ & $\mathrm{RZ}$ & $\Sigma \mathrm{UX}$ & $\Sigma \mathrm{UY}$ & $\Sigma \mathrm{RZ}$ \\
\hline 1 & 4.407 & 0.7066 & 0.0042 & 0 & 0.7066 & 0.0042 & 0 \\
2 & 4.407 & 0.0042 & 0.7066 & 0 & 0.7108 & 0.7108 & 0 \\
3 & 3.462 & 0 & 0 & 0.8012 & 0.7108 & 0.7108 & 0.8012 \\
4 & 1.255 & 0.1624 & 0.0009 & 0 & 0.8732 & 0.7117 & 0.8012 \\
5 & 1.255 & 0.0009 & 0.1624 & 0 & 0.8742 & 0.8742 & 0.8012 \\
6 & 1.147 & 0 & 0 & 0.0921 & 0.8742 & 0.8742 & 0.8933 \\
\hline
\end{tabular}

Table 5. Modal periods and mass participation ratios of Model 3

\begin{tabular}{llllllll}
\hline Mode & Period $(\mathrm{s})$ & $\mathrm{UX}$ & $\mathrm{UY}$ & $\mathrm{RZ}$ & $\Sigma \mathrm{UX}$ & $\Sigma \mathrm{UY}$ & $\Sigma \mathrm{RZ}$ \\
\hline 1 & 4.453 & 0.3757 & 0.3387 & 0 & 0.3757 & 0.3387 & 0 \\
2 & 4.446 & 0.3388 & 0.3758 & 0 & 0.7145 & 0.7145 & 0 \\
3 & 3.167 & 0 & 0 & 0.8199 & 0.7145 & 0.7145 & 0.8176 \\
4 & 1.282 & 0.1246 & 0.0323 & 0 & 0.8391 & 0.8678 & 0.8176 \\
5 & 1.281 & 0.0323 & 0.1246 & 0 & 0.8678 & 0.8678 & 0.8176 \\
6 & 1.056 & 0 & 0 & 0.088 & 0.8678 & 0.8678 & 0.9062 \\
\hline
\end{tabular}


Table 6. The maximum lateral displacement values of structural models

\begin{tabular}{cccc}
\hline \multirow{2}{*}{ Earthquake } & \multicolumn{3}{c}{ Maximum values (mm) } \\
\cline { 2 - 4 } & Model 1 & Model 2 & Model 3 \\
\hline Imperial Valley & 412.813 & 383.751 & 398.95 \\
Kobe & 435.782 & 368.551 & 374.15 \\
Kocaeli & 397.291 & 376.29 & 373.427 \\
\hline
\end{tabular}

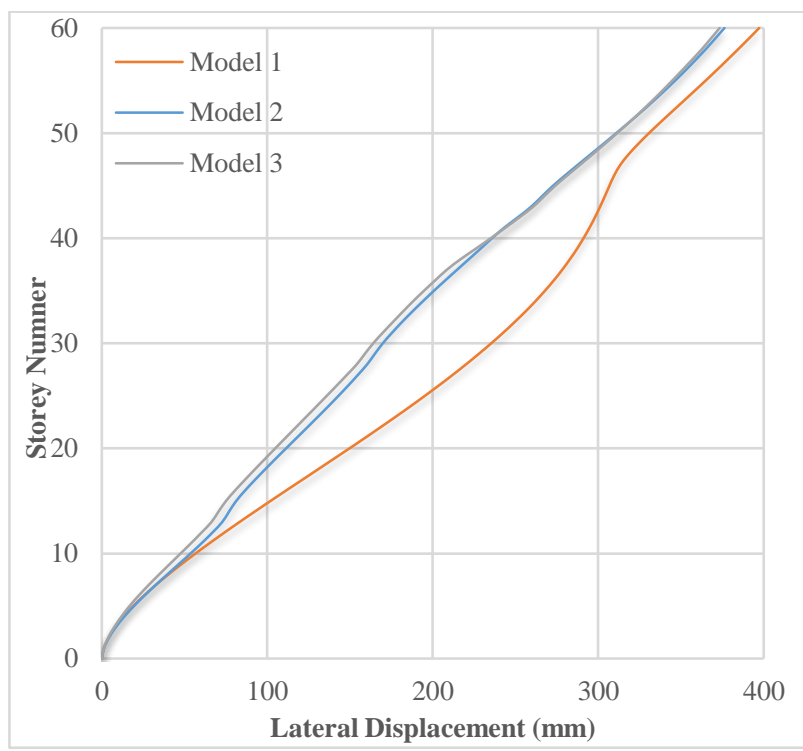

Fig. 9. Lateral maximum displacement curve of structural models under the scaled Kocaeli record

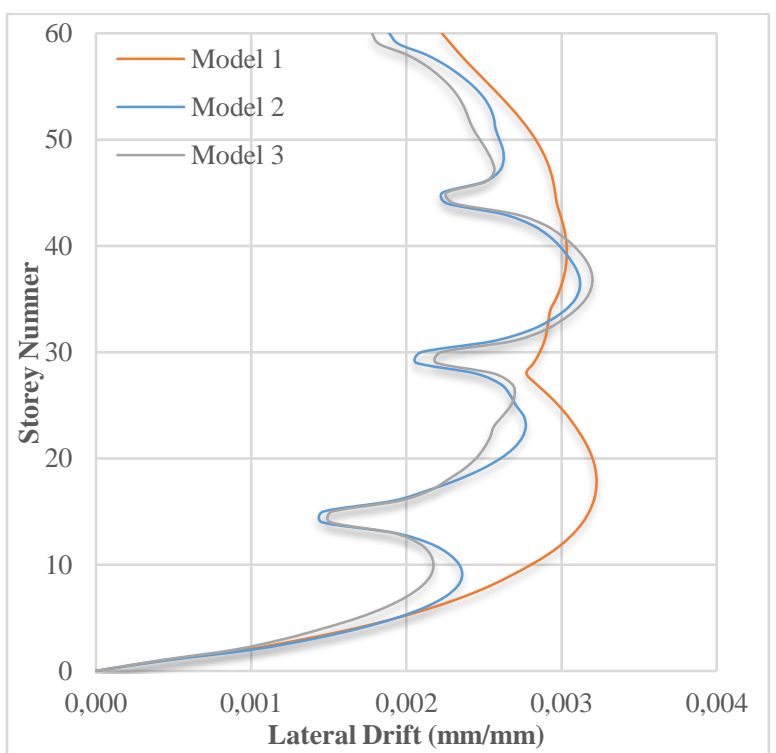

Fig. 10. Lateral maximum drift curve of structural models under the scaled Kocaeli record 
When the tables and curves are examined, it is observed that the lateral displacements of the models with outrigger and belt truss systems are close to each other. These two systems are effective in the decrease of lateral displacement and drifts for the structures under lateral loading. Also, the drifts of stories where outrigger and belt-truss systems are located are smaller than those of other stories.

The maximum lateral displacement and lateral drift curves of the structural models under other two earthquake records are presented in Figs. 11-14, respectively. The results of these records show strongly similar behavior with those of the Kocaeli record. However, some obvious differences arise due to the effect of earthquake characteristics, especially for the results of the Kobe record. According to these results, it can be said that the outrigger and belt-truss systems increase the stiffness of the stories where they are located.

Maximum base shear forces of the core and system for structural models are presented in Table 7.

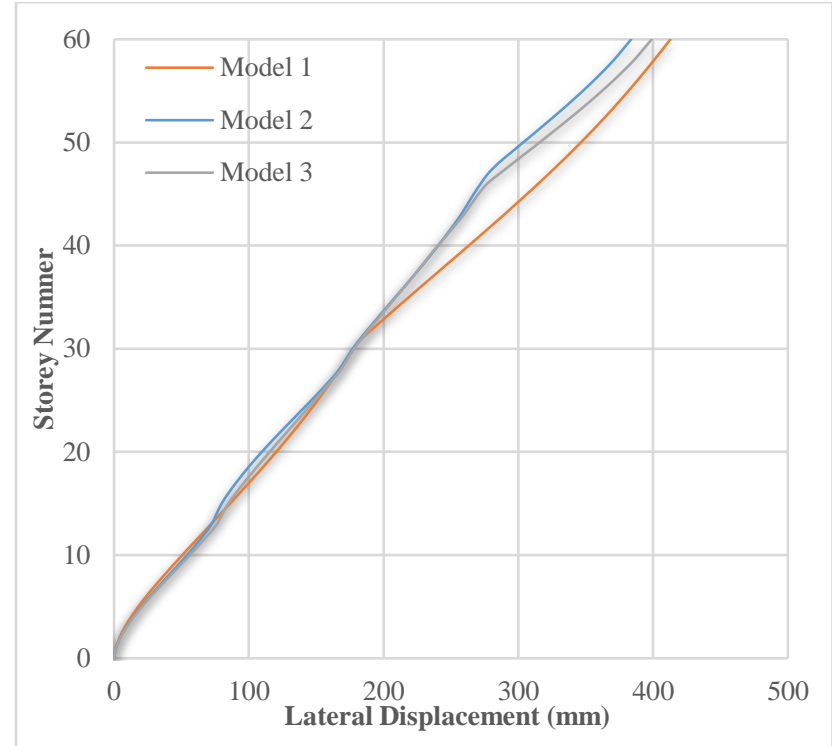

Fig. 11. Lateral maximum displacement curve of structural models under the scaled Imperial Valley record

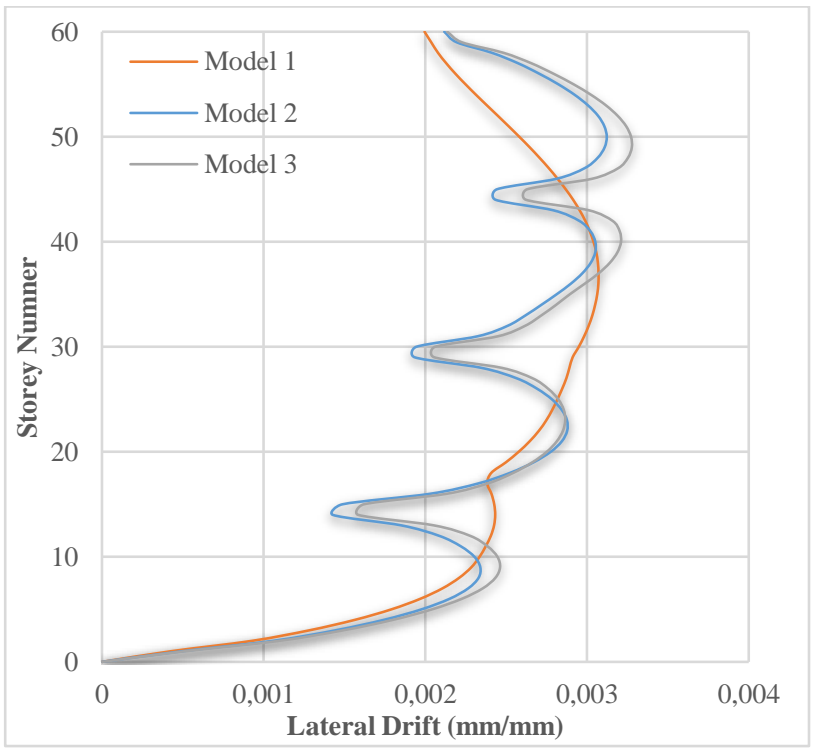

Fig. 12. Lateral maximum drift curve of structural models under the scaled Imperial Valley record 


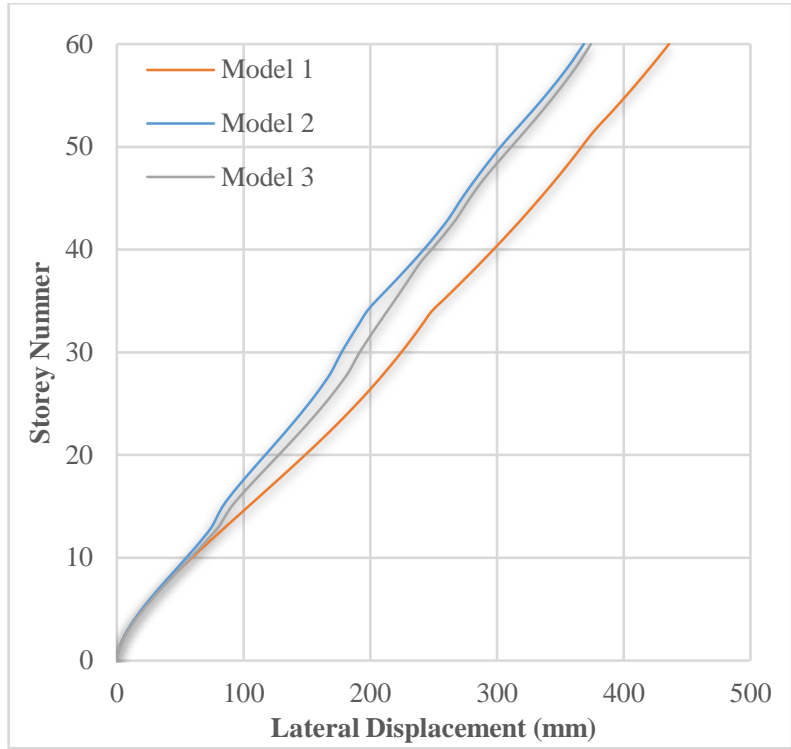

Fig. 13. Lateral maximum displacement curve of structural models under the scaled Kobe record

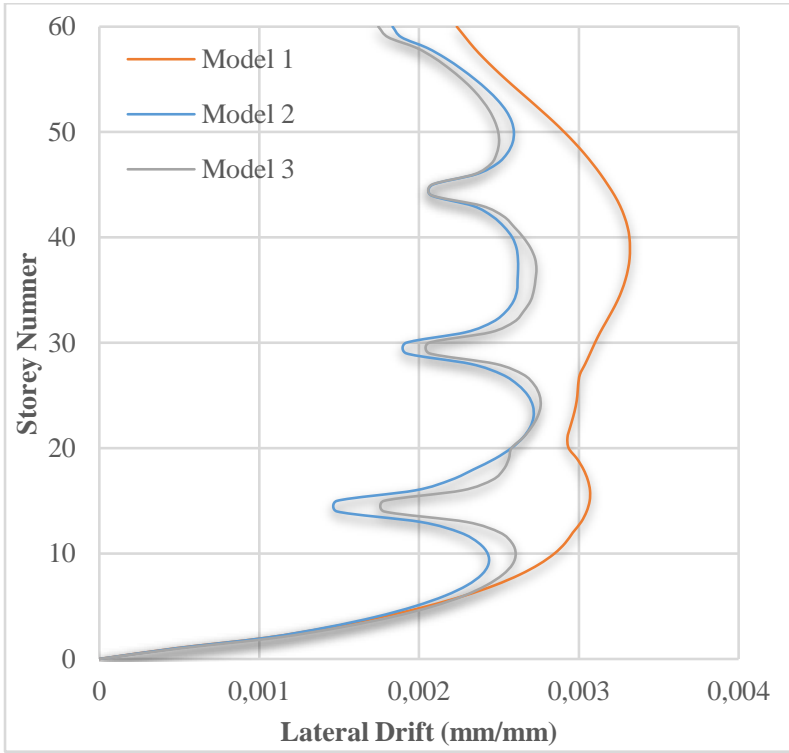

Fig. 14. Lateral maximum drift curve of structural models under the scaled Kobe record

Table 7. Maximum base shear forces of the core and the system for structural models

\begin{tabular}{ccccccccccc}
\hline \multicolumn{1}{c}{ Maximum values of the base shear force $(\mathrm{kN})$} \\
\hline \multirow{2}{*}{ Earthquake } & \multicolumn{3}{c}{ Model 1 } & \multicolumn{3}{c}{ Model 2 } & \multicolumn{3}{c}{ Model 3 } \\
\cline { 2 - 12 } & Core & System & Rate \% & Core & System & Rate \% & Core & System & Rate \% \\
\hline Imperial Valley & 22158 & 42450 & 52.2 & 26460 & 51280 & 51.6 & 27624 & 53536 & 51.6 \\
Kobe & 24484 & 47641 & 51.4 & 27040 & 52394 & 51.6 & 26158 & 50831 & 51.4 \\
Kocaeli & 30076 & 58124 & 51.7 & 27698 & 53474 & 51.8 & 25232 & 48787 & 51.7 \\
\hline
\end{tabular}


The same table also gives the ratio of core's base shear to that of the system. When Table 7 are examined, the ratio of core's base shear to that of the system at all structural models for all earthquake records almost remains the same and this ratio is around $50 \%$. Maximum base bending moment of the core and total overturning moment of the system for structural models are given in Table 8 . The same table also includes the ratio of core's bending moment to overturning moment of the system and this ratio remains around $4-5 \%$.

Additionally, variations of maximum shear force of the core, maximum bending moment of the core and maximum axial force of the outer columns along the structure's height under the scaled Kocaeli earthquake record are given in Figs. 15-17, respectively. There is an increase in the shear force of the core at the outrigger and belt truss levels is observed from Fig. 15. It can be seen in Fig. 16 that when the outrigger and belt truss systems are added to the shear wall-framed system, the bending moment of the core wall has changed somewhat at the added levels. When Fig. 17 is examined, the axial forces of the outer columns considerably vary at the outrigger and belt truss levels and increase towards the base of structure.

Variations of maximum shear force of the core, maximum bending moment of the core and maximum axial force of the outer columns along the structure's height under other two earthquake records are given in Figs. 18-23, respectively. Although the results of these records are similar to the related results of the Kocaeli record, there are some differences depending on the earthquake characteristics.
In the light of the results obtained, it has been observed that the outrigger and belt truss systems contribute to the lateral and torsional stiffness of the structure. Therefore, these systems generally led to a reduction in the lateral displacement and drifts. The outrigger and belt truss systems affect the internal forces of the structural elements, causing sudden changes in these forces at the levels they are attached to the structure, and especially significant increases in the axial forces of the outer columns.

\section{Conclusions}

In this study, the effectiveness of outrigger and belt truss systems on the seismic behavior of high-rise buildings were assessed. For this purpose, three building models were formed, which are shear wallframed system, shear wall-framed system with traditional outriggers and shear wall-framed system with belt trusses, respectively. All building models are 60-story and have the same floor plans. Linear earthquake responses of three structural models were performed by using modal time history analysis method. Lateral displacements and drifts of the structure, internal forces of the structural elements were obtained. These results of three structural models were compared with each other and assessed. For earthquake input, three real earthquake records were selected. These records were scaled in accordance with the DD2 level earthquake design spectrum defined in Turkish Building Earthquake Standards (2018) and used in the analyses.

Table 8. Maximum base bending moment of the core and total overturning moment of the system for structural models

\begin{tabular}{lcccccccccc}
\hline \multicolumn{1}{c}{ Maximum values of the moment $(\mathrm{kNm})$} \\
\hline \multirow{2}{*}{ Earthquake } & \multicolumn{3}{c}{ Model 1 } & \multicolumn{3}{c}{ Model 2 } & \multicolumn{3}{c}{ Model 3 } \\
\cline { 2 - 11 } & Core & System & Rate \% & Core & System & Rate \% & Core & System & Rate \% \\
\hline Imperial Valley & 169072 & 3498838 & 4.83 & 182626 & 3919807 & 4.66 & 188872 & 4004454 & 4.71 \\
Kobe & 180252 & 4274228 & 4.24 & 187136 & 3928585 & 4.76 & 190164 & 3965913 & 4.80 \\
Kocaeli & 192408 & 3576482 & 5.38 & 177536 & 4056758 & 4.37 & 173266 & 3848301 & 4.50 \\
\hline
\end{tabular}




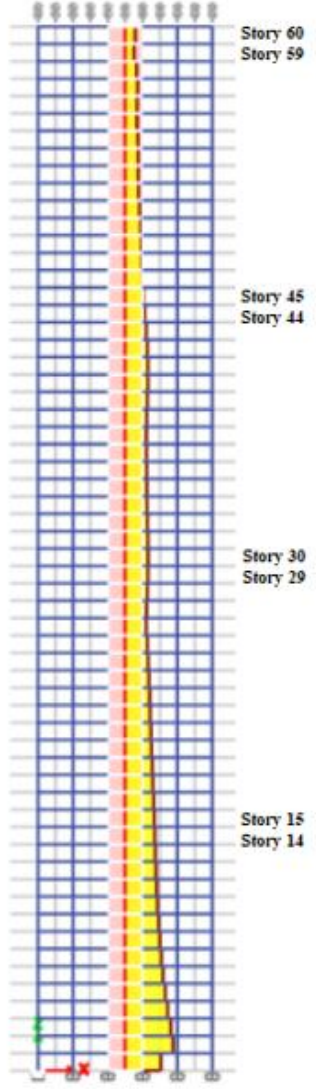

Model 1

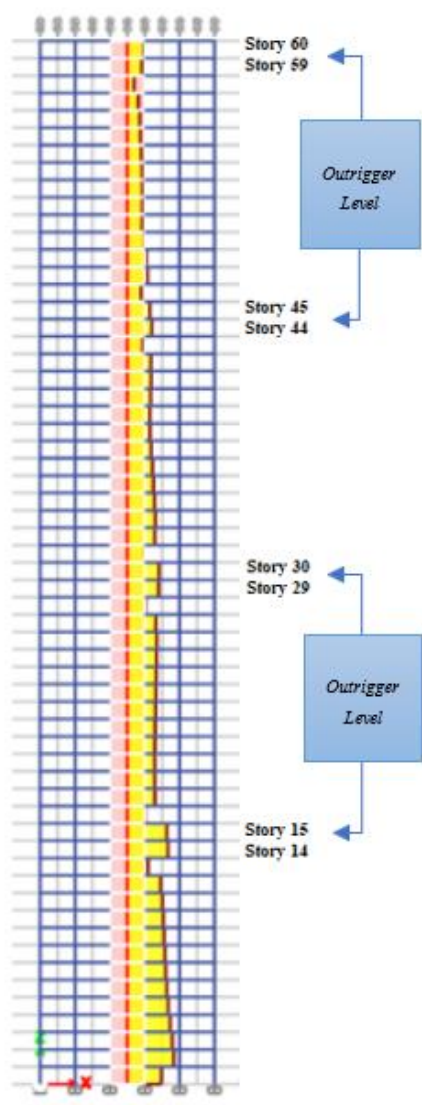

Model 2

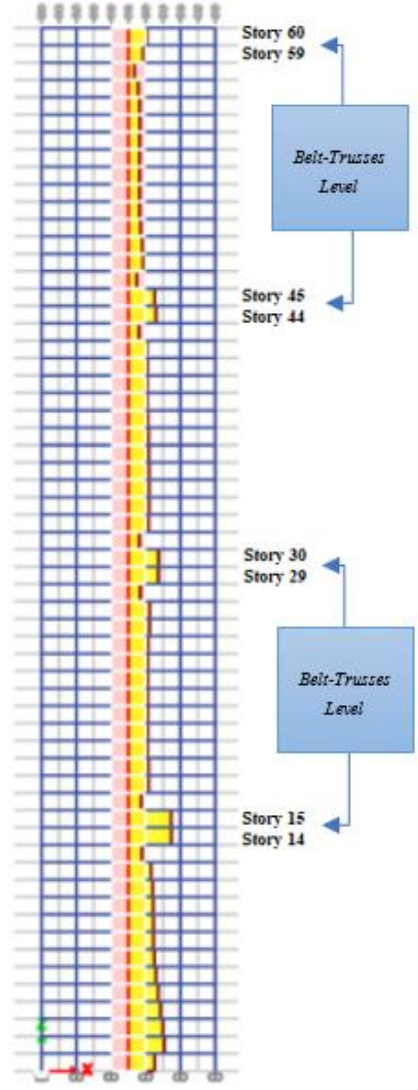

Model 3

Fig. 15. Maximum shear force variation of the core along the structure's height under the scaled Kocaeli earthquake record 


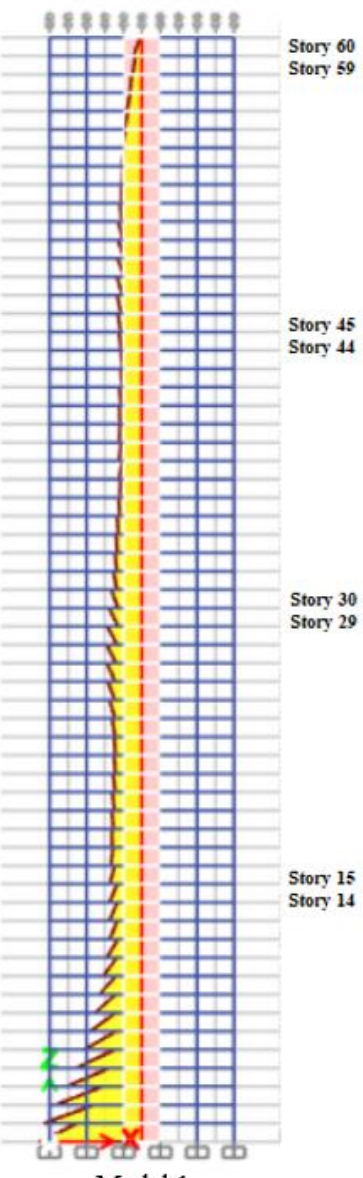

Model 1

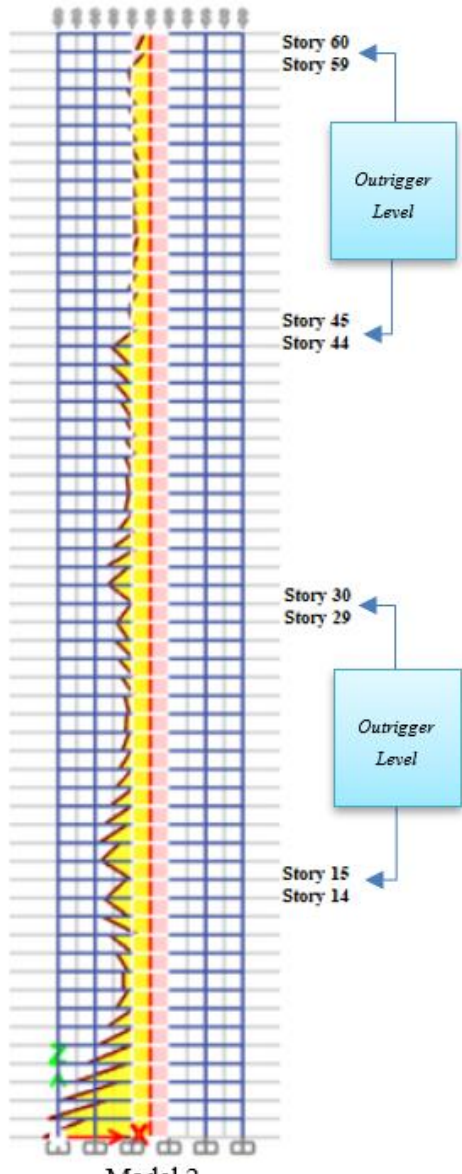

Model 2

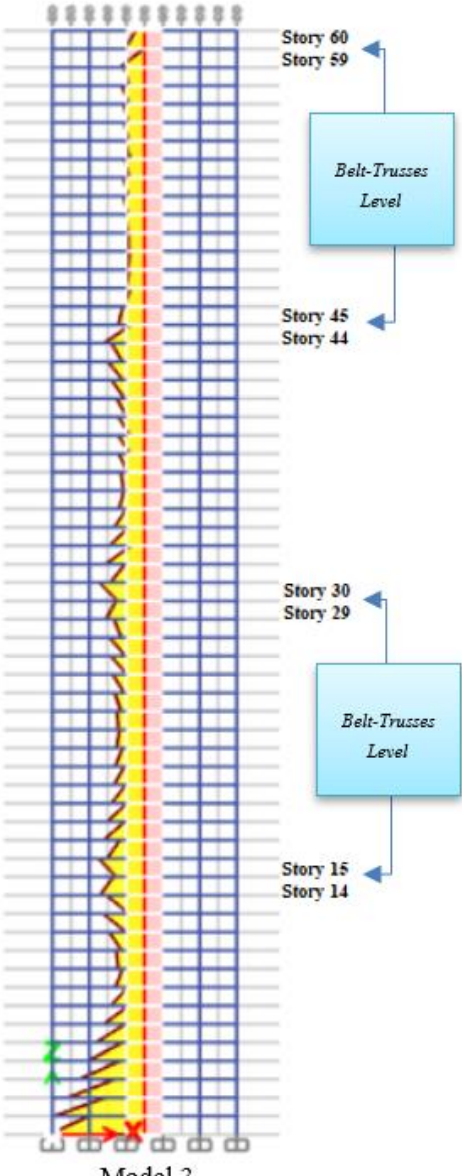

Model 3

Fig. 16. Maximum bending moment variation of the core along the structure's height under the scaled Kocaeli earthquake record 


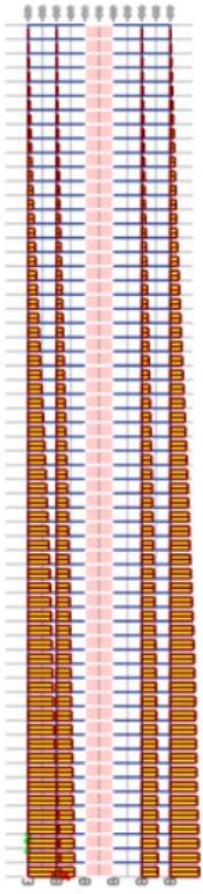

Model 1

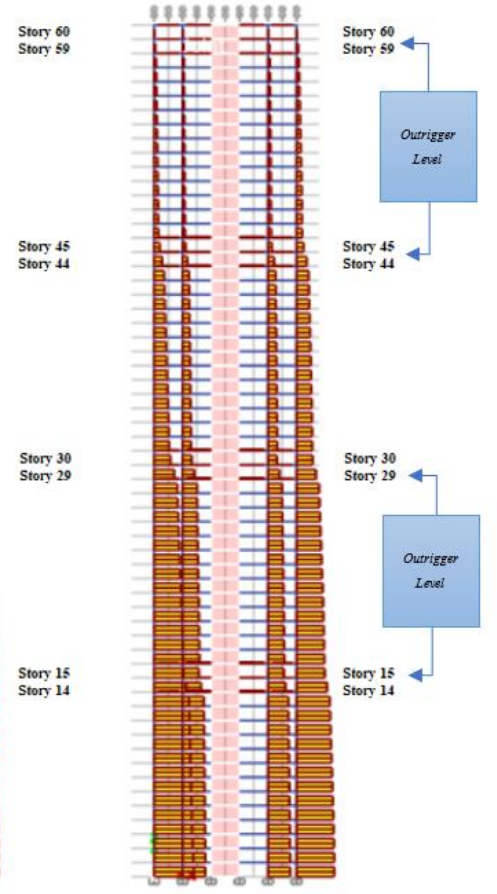

Model 2

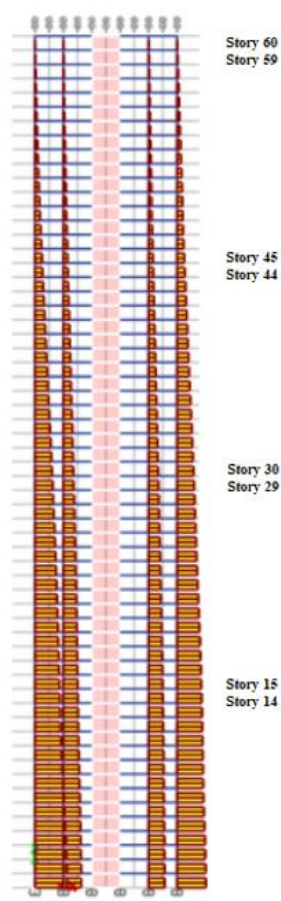

Model 1

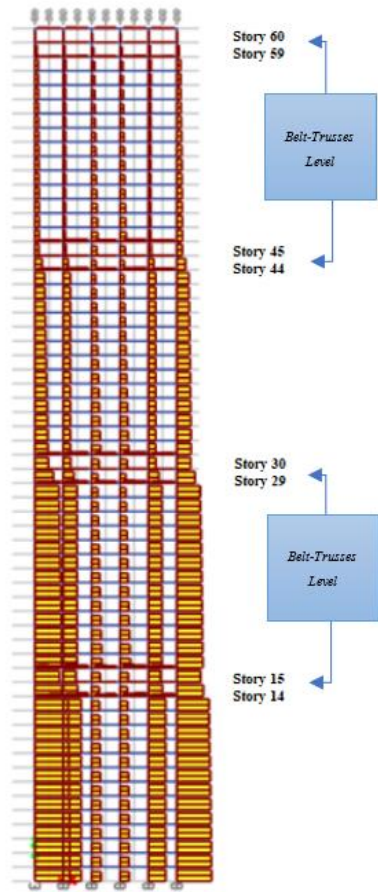

Model 3

Fig. 17. Maximum axial force variation of the outer columns along the structure's height under the scaled Kocaeli earthquake record 


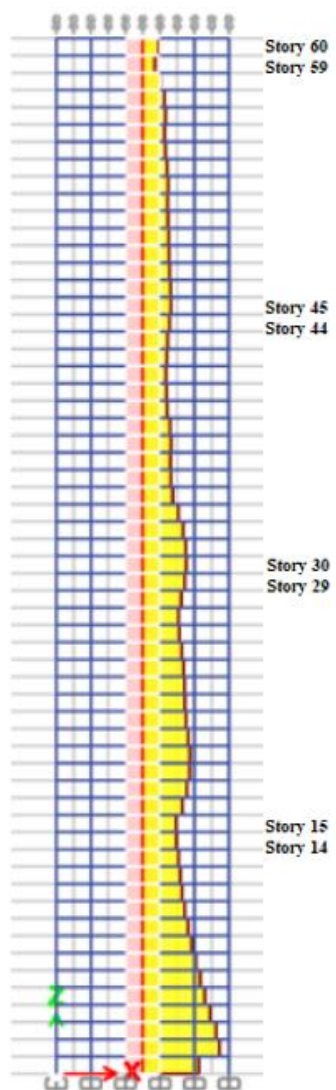

Model 1

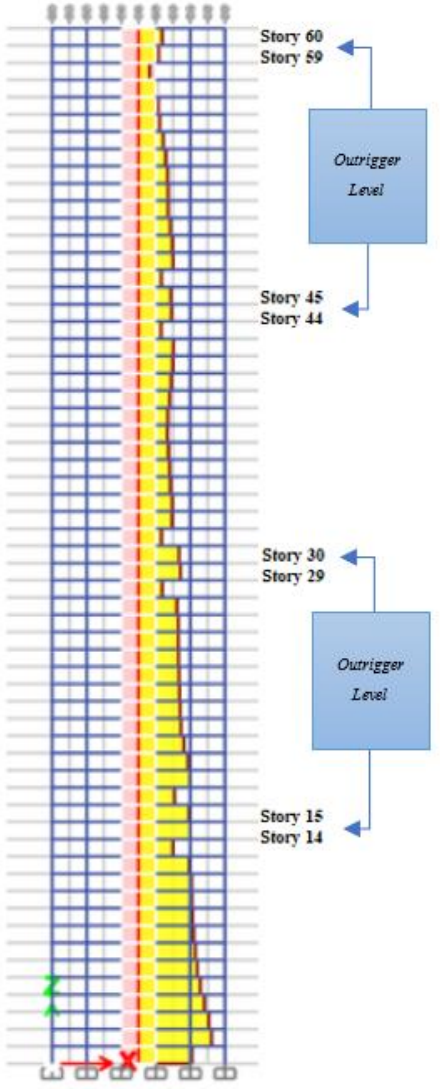

Model 2

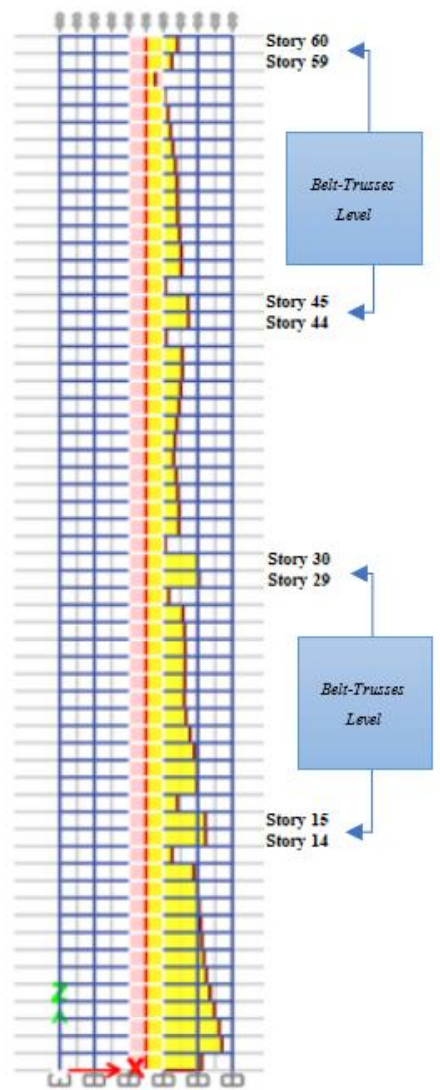

Model 3

Fig. 18. Maximum shear force variation of the core along the structure's height under the scaled Imperial Valley earthquake record 


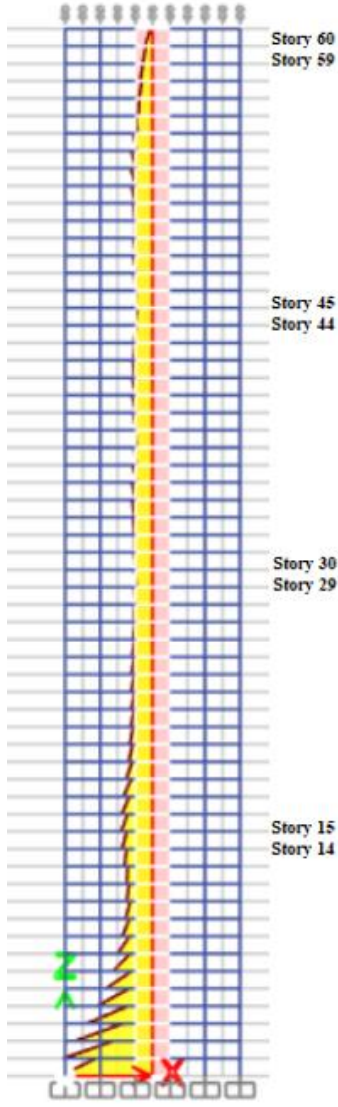

Model 1

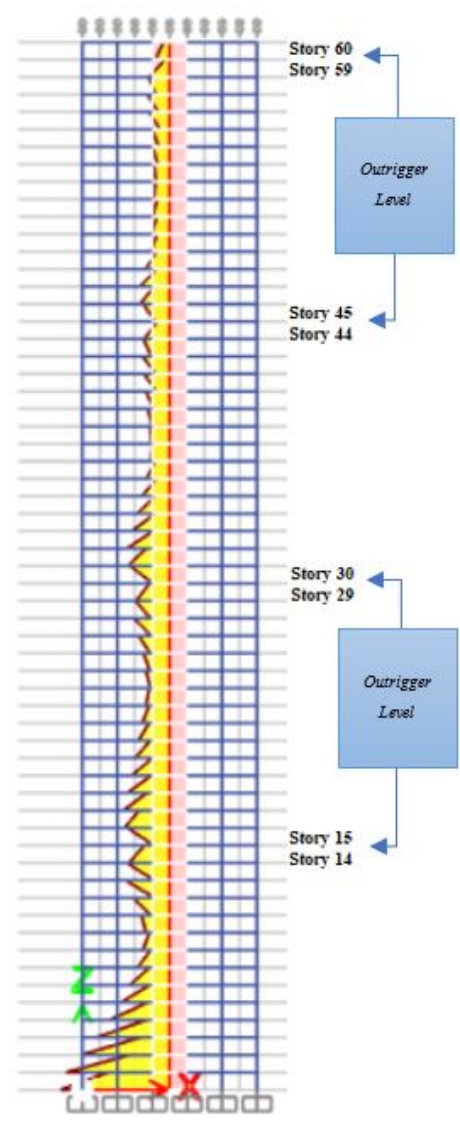

Model 2

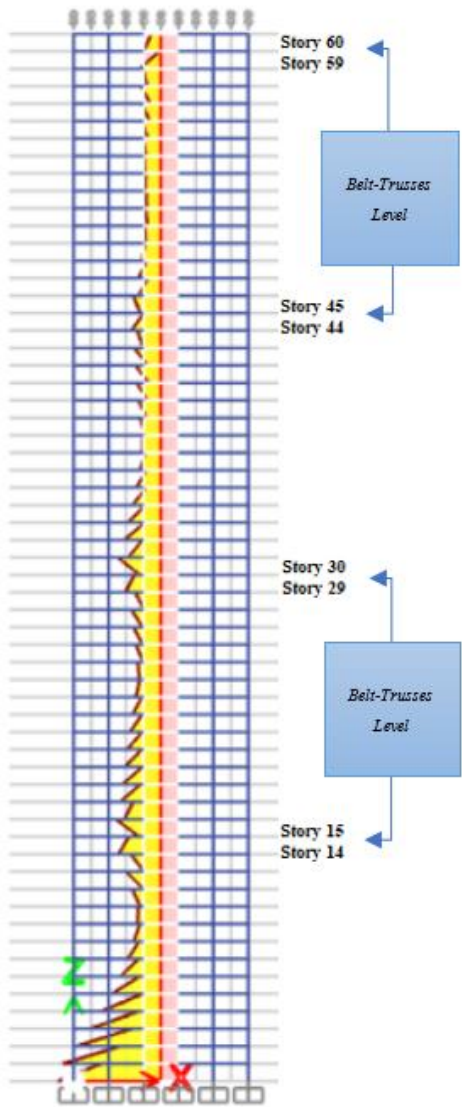

Model 3

Fig. 19. Maximum bending moment variation of the core along the structure's height under the scaled Imperial Valley earthquake record 


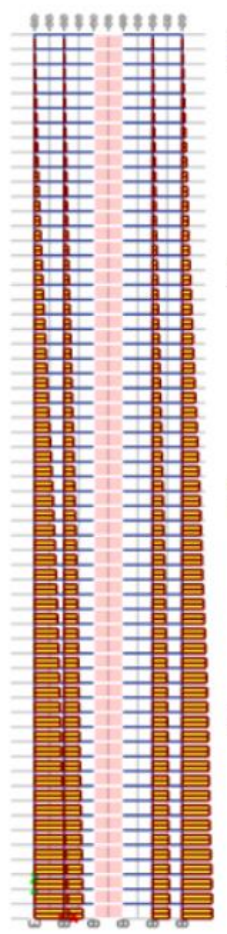

Model 1

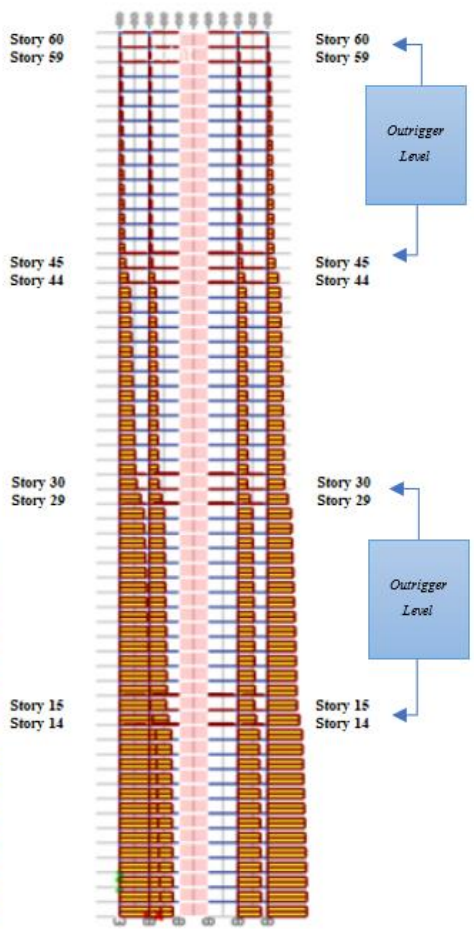

Model 2

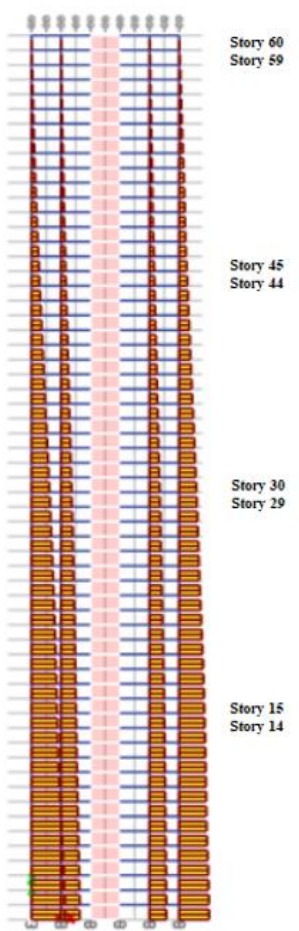

Model 1

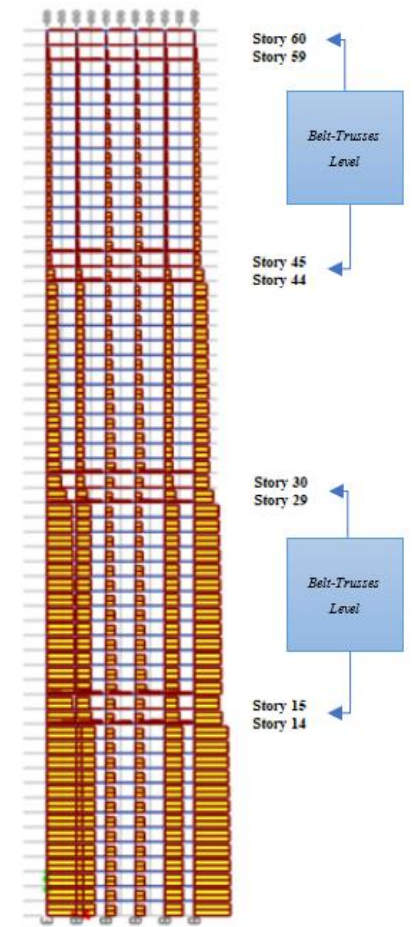

Model 3

Fig. 20. Maximum axial force variation of the outer columns along the structure's height under the scaled Imperial Valley earthquake record 


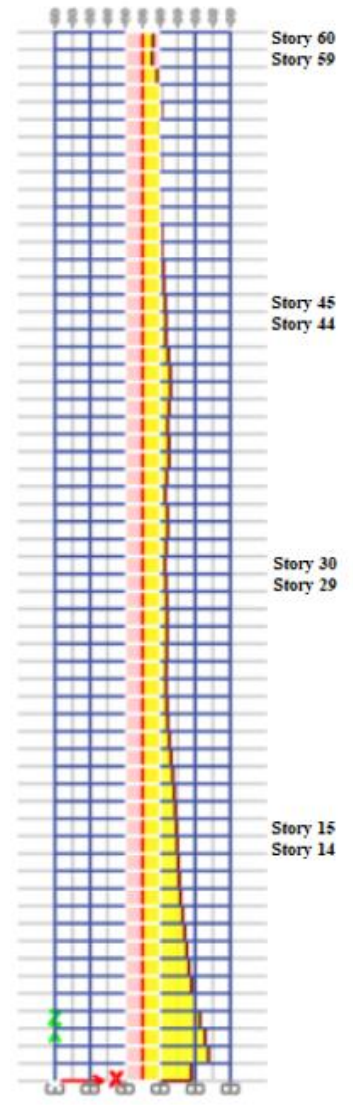

Model 1

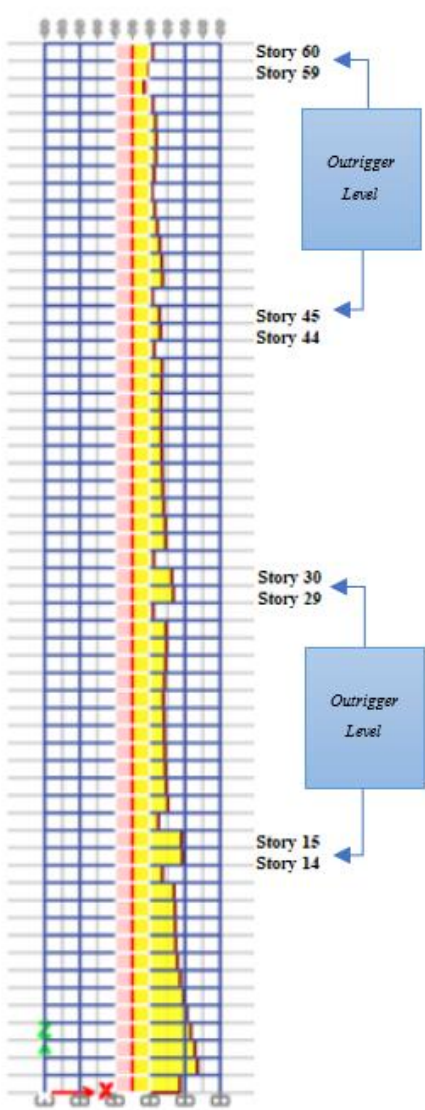

Model 2

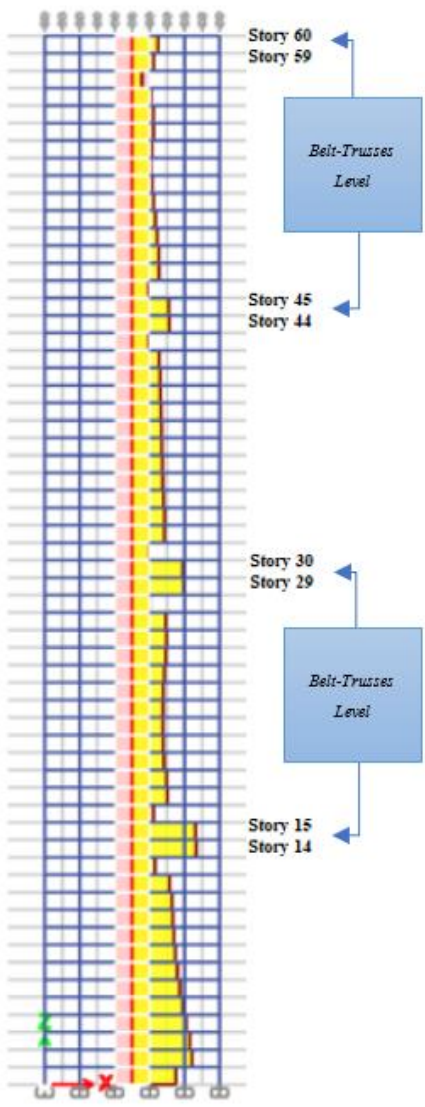

Model 3

Fig. 21. Maximum shear force variation of the core along the structure's height under the scaled Kobe earthquake record 


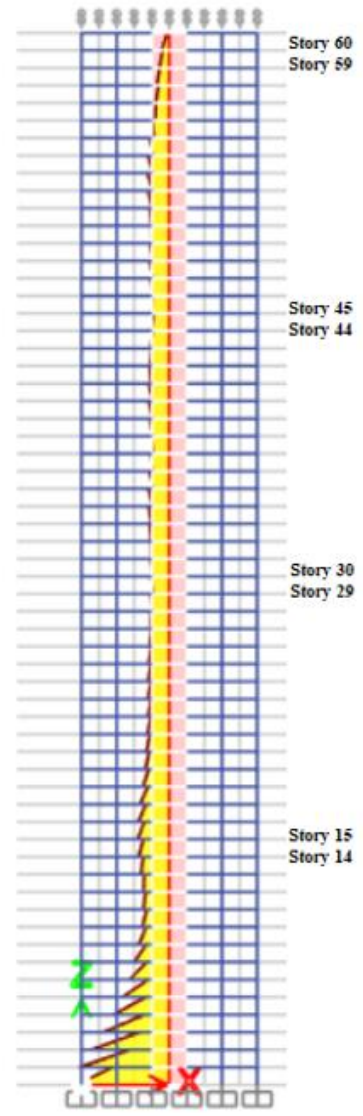

Model 1

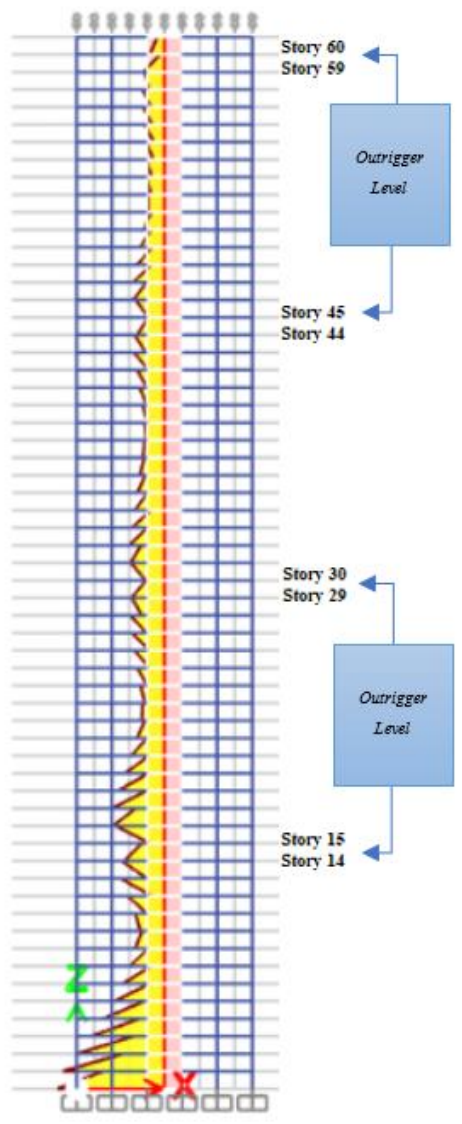

Model 2

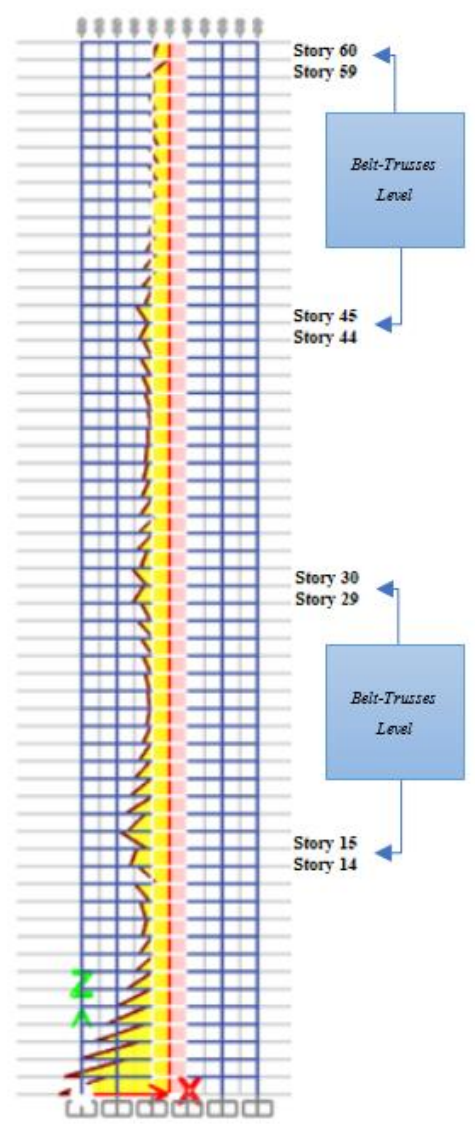

Model 3

Fig. 22. Maximum bending moment variation of the core along the structure's height under the scaled Kobe earthquake record 


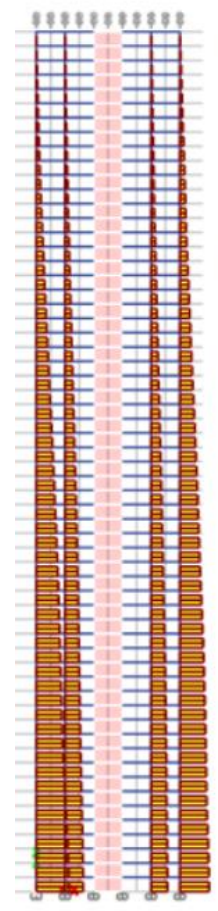

Model 1
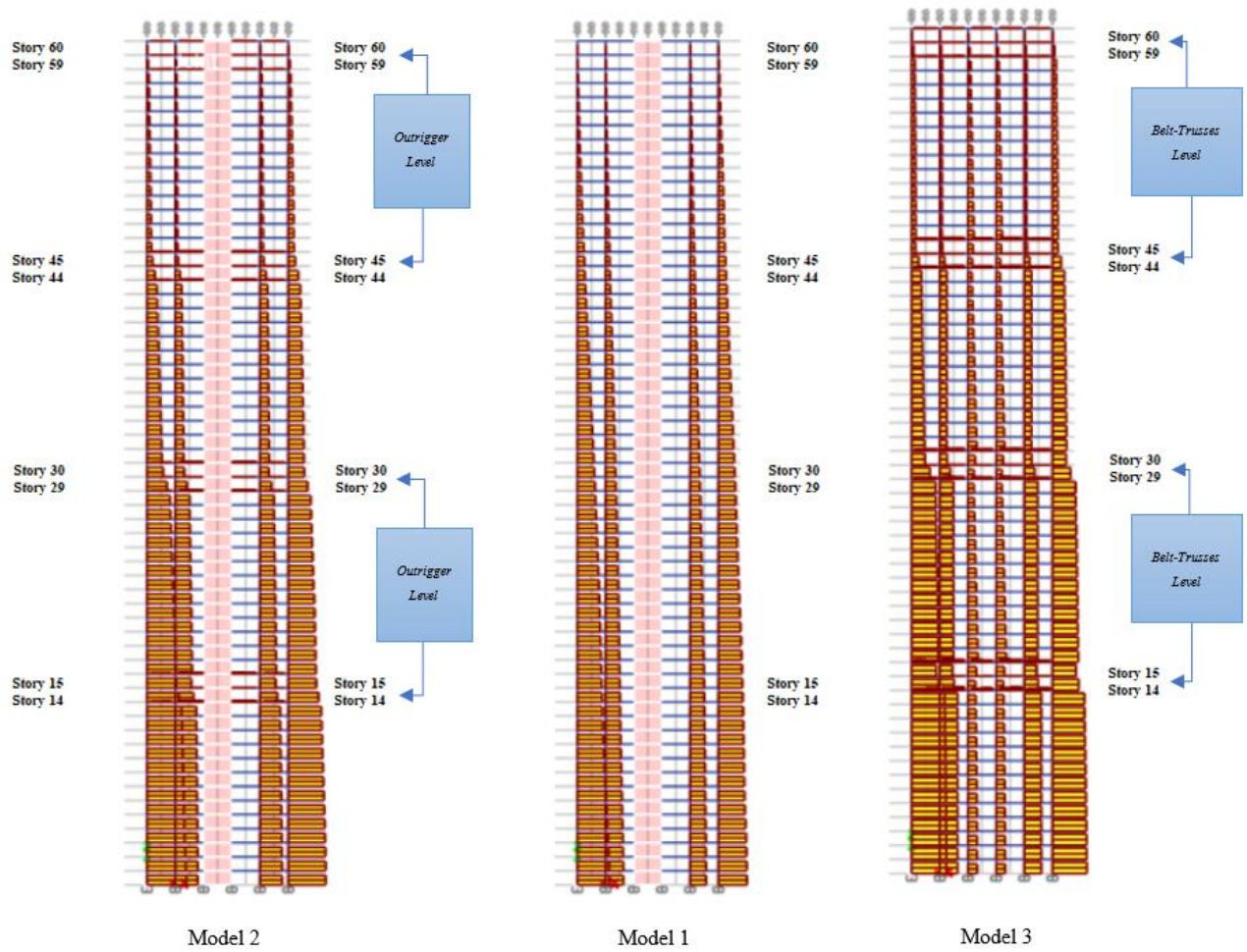

Fig. 23 Maximum axial force variation of the outer columns along the structure's height under the scaled Kobe earthquake record

The following conclusions can be drawn from the study:

1. With the addition of the outrigger and belt-truss systems to the shear-wall framed system, the translational and torsional periods of structure were decreased. When these systems are used, the lateral and torsional stiffnesses of the structure increase. In particular, the outrigger systems contributed more to the lateral stiffness while the belt-truss systems contributed more to the torsional stiffness.

2. In previous studies, it has observed that the horizontal displacements under lateral static loads significantly reduced by adding outriggers to the shear wall-framed system $[15,22]$. In the dynamic analysis, with the addition of outriggers and belt-trusses to the shear wallframed system, the lateral displacements of the structure system did not sufficiently reduce according to the results observed in the case of static loading. This situation is thought to occur due to the following reasons: While static responses vary only depending on the stiffness of the structure, dynamic responses vary depending on the stiffness, mass and damping of the structure as well as the characteristics of ground motion.

3. The lateral drifts of stories where the outriggers and belt-trusses are located were decreased compared to those of other stories. Because the outrigger and belt-truss systems increase the lateral stiffness of the story where they are located.

4. The outrigger and belt truss systems affect the internal forces of the structural elements, causing sudden changes in these forces at the levels they are attached to the structure, and especially significant increases in the axial forces of the outer columns.

5. Belt truss systems are as effective as outrigger systems. Problems arising in the use of outrigger were eliminated by the use of the belt truss systems. 


\section{Declaration of conflicting interests}

The author(s) declared no potential conflicts of interest with respect to the research, authorship, and/or publication of this article.

\section{References}

[1] Taranath BS (1974) Optimum belt truss location for high-rise structures. Engineering Journal AISC 11: 18-21.

[2] Taranath BS (1975) Optimum belt truss location for high-rise structures. Structural Engineer 53: 345347.

[3] McNabb JB, Muvdi BB (1975) Drift reduction factors for belted high-rise structures. Engineering Journal AISC 12: 88-91.

[4] McNabb JB, Muvdi BB (1977) Discussion: drift reduction factors for belted high-rise structures. Engineering Journal AISC 14:44-47.

[5] Smith BS, Salim I (1981) Parameter study of outrigger-braced tall building structures. ASCE Journal of the Structural Division 107(10): 20012014.

[6] Nair RS (1998) Belt trusses and basement as "virtual" outriggers for tall buildings. Engineering Journal AISC Fourth Quarter: 140-146.

[7] Hoenderkamp JCD, Snijder HH (2000) Simplified analysis of façade rigger braced high-rise structures. The Structural Design of Tall Buildings and Special Buildings 9: 309-319.

[8] Hoenderkamp JCD, Bakker MCB (2003) Analysis of high-rise braced frames with outriggers. The Structural Design of Tall Buildings and Special Buildings 12: 335-350.

[9] Hoenderkamp JCD (2008) Second outrigger at optimum location on high-rise shear-wall. The Structural Design of Tall Buildings and Special Buildings 17: 619-634.

[10] Rahgozar R, Ahmedi AR, Hosseini O, Malekinejad M (2011) A simple mathematical model for static analysis of tall buildings with two outrigger-belt truss systems. Structural Engineering and Mechanics 40(1):65-84.

[11] Kamath K, Divya N, Rao AU (2012) A study on static and dynamic behavior of outrigger structural system for tall buildings. Bonfring International Journal of Industrial Engineering and Management Science 2(4): 15-20.

[12] Nanduri RK, Suresh B, Hussein I (2013) Optimum position of outrigger system for high-rise reinforced concrete buildings under wind and earthquake loadings. American Journal of Engineering Research 2(8): 76-89.

[13] Zhou Y, Zhang C, Lu X (2016) An inter-story driftbased parameter analysis of the optimal location of outriggers in tall buildings. The Structural Design of Tall Buildings and Special Buildings 25: 215231.

[14] Patil DM, Sangle KK (2016) Seismic behaviour of outrigger braced systems in high rise 2-D steel buildings. The Elsevier Journal Structure 8: 1-16.

[15] Dedeoğlu İÖ. Lateral load response of reinforced concrete high-rise buildings with outrigger system. MSc Thesis. Ege University, 2017.

[16] Calayır Y, Dedeoğlu İÖ. Earthquake response of reinforced concrete tall buildings with outriggers. $4^{\text {th }}$ International Conference on Earthquake Engineering and Seismology (ICEES), 11-13 October 2017, Eskişehir, Turkey, Proceedings No: 3800 .

[17] Kamgar R, Rahgozar R (2017) Determination of optimum location for flexible outrigger systems in tall buildings with constant cross section consisting of framed tube, shear core, belt truss and outrigger system using energy method. International Journal of Steel Structures 17(1): 1-8.

[18] Rabee K, Juan S (2018) Analysis of outriggerbraced reinforced concrete supertall buildings: Core-supported and tube-in-tube lateral systems. The Structural Design of Tall Buildings and Special Buildings 28: e1567.

[19] Mohsenali S, Vahid B, Ali G (2019) Analysis of coupled steel plate shear walls with outrigger system for tall buildings. Iranian Journal of Science and Technology Transactions of Civil Engineering 44: 151-163.

[20] Lin P, Takeuchi T (2019) Seismic performance of buckling-restrained brace outrigger system in various configurations. Japan Architectural Review 2(4): 392-408.

[21] Fathy E (2020) Seismic assessment of thin steel plate shear walls with outrigger system. Structural Engineering and Mechanics 74(2): 267-282.

[22] Dedeoğlu İÖ, Calayır Y, Arısoy B (2020) An investigation on RC high-rise structures with and without outriggers under lateral static loads. Sigma Journal of Engineering and Natural Sciences 38 (1): 191-211.

[23] Akbar V, Vahid K (2020) Effect of outrigger panels on seismic performance of steel plate shear wall structural system. International Journal of Steel Structures 20(4): 1180-1192. 
[24] Kirruti P, Balkis AP (2020) Seismic performance assessment of steel bracing systems in high-rise reinforced concrete structures. Journal of Structural Engineering \& Applied Mechanics 3(2): 110-126.

[25] Taranath BS. Reinforced Concrete Design of Tall Buildings. CRC Press, New York, 2010.
[26] PEER (2017) Pacific Earthquake Engineering Research Center Strong Ground Motion Database. http://ngawest2.berkeley.edu.

[27] ETABS Integrated Analysis Design and Drafting of Building Systems (2015) Computer and Structures Incorporation, Berkeley, California, USA, 2015. 